\title{
O BRINCAR NO PRIMEIRO ANO: PRODUÇÃO DO CONHECIMENTO A PARTIR DAS TESES E DISSERTAÇÕES ACERCA DO INGRESSO DA CRIANÇA DE SEIS ANOS.
}

Leonardo de Angelo Orlandi; Jéssika Naiara da Silva; José Milton de Lima; Márcia Regina Canhoto de Lima

Grupo de Pesquisa Cultura Corporal: Saberes e Fazeres. Programa de Pós-Graduação em Educação UNESP/Presidente Prudente. E-mail: leo_angeloorlandi@hotmail.com.

\section{RESUMO}

Esta pesquisa tem como temática o brincar no ingresso da criança de seis anos no Ensino Fundamental e apresenta como objeto de estudo as produções acadêmicas de tal temática a partir de 2006. Estabelece como objetivo central: identificar nas produções dos programas de pósgraduação como o Ensino Fundamental de nove anos têm sido estabelecido e implementado em relação aos sujeitos escolares. A investigação de natureza qualitativa adotou como metodologia a pesquisa bibliográfica. Para tal fim, o estudo analisou 42 dissertações e 4 teses localizadas na internet por meio dos bancos de dados da CAPES, da BDTD, do CNPq e do Domínio Público. Na pesquisa bibliográfica realizada, foram utilizados os seguintes descritores: "Brincadeira e Ensino Fundamental de nove anos", "Educação Infantil e Ensino Fundamental". Os resultados demonstraram que as mudanças foram ínfimas em relação as práticas destinadas as crianças de seis anos de idade, além de dicotomias entre o discurso dos documentos públicos e as práticas pedagógicas.

Palavras-chave: Ensino Fundamental; Infância; Aprendizagem; Criança; Educação.

\section{INTRODUÇÃO E OBJETIVO}

Este artigo é resultado de um recorte da dissertação de mestrado junto ao Programa de Pós-Graduação em Educação da Faculdade de Ciências e Tecnologia - Unesp, Campus de Presidente Prudente que foi desenvolvida em uma Instituição Municipal de Ensino Fundamental, no município de Presidente Prudente. O interesse em investigar a brincadeira e o ensino fundamental de nove anos adveio da constatação de que essa ampliação é pouco comprendida pelos sujeitos escolares e, também, de que os descompassos decorrentes do ingresso das crianças de cinco a seis anos no primeiro ano desse nível de ensino, estão gerando diversos paradoxos propícios para reflexões na forma de conceber a educação para a infância. Diante dessa realidade, compreender as pesquisas sobre o tema proposto podem contribuir para avanços na qualidade do trabalho pedagógico no primeiro ano do Ensino Fundamental.

No contexto em que vivemos, a infância tem sido considerada um dado universal e categoria natural. As instituições de educação para crianças pouco favorecem a experiência com o conhecimento científico, tampouco com a cultura, seja esta entendida em sua dimensão de produção nas relações sociais cotidianas, ou como produção historicamente acumulada, presente 
na literatura, na música, na dança, no teatro, na brincadeira, enfim, na produção artística, histórica e cultural. Essa realidade, revela uma tendência tradicional e tecnicista que não dá conta das dificuldades de aprendizagem na infância.

No primeiro ano do Ensino Fundamental, o problema se acentua, principalmente pelo descompasso entre a redução do tempo de permanência da criança na Educação Infantil e sua ampliação no Ensino Fundamental, no qual são gerados contextos artificiais que obrigam as crianças a se adaptarem a situações pedagógicas até mesmo desprovidas de sentido para elas.

Nesse contexto, "embora a Educação Infantil e o Ensino Fundamental sejam frequentemente separados, do ponto de vista da criança não há fragmentação" (KRAMER, 2006, p. 810). Os aspectos burocráticos são os que muitas vezes distinguem tais instituições, deixando de lado o que seria capaz de vinculá-las: a experiência com a cultura. Ainda que a elaboração dos conteúdos suscite diversas questões nos dois segmentos, ambos têm como objetivo "assegurar a apropriação e a construção dos conhecimentos que se fazem presentes no brincar, no criar e no aprender" (KRAMER, 2006, p. 810).

A partir da aprovação da Lei no 11.274 (BRASIL, 2006), o Ensino Fundamental passou a ter a duração de nove anos, com a inclusão obrigatória das crianças de seis anos nesse estágio da escolaridade. Essa determinação, que consolidou a proposição de expansão desse nível de ensino contida na Lei de Diretrizes e Bases da Educação Nacional, Lei no 9.394/96, e no Plano Nacional de Educação - PNE, Lei no 10.172 (BRASIL, 2001), trouxe para o sistema educacional brasileiro um número maior de crianças, especialmente aquelas oriundas dos setores populares, uma vez que as de classes média e alta já se encontravam, majoritariamente, incorporadas ao sistema.

Nessa ótica, a implementação do ensino de nove anos e, consequentemente, a inserção de crianças com seis anos de idade no Ensino Fundamental transformam-se em verdadeiro tormento para aquelas que são obrigadas a se adaptar a situações e conteúdos que não lhes fazem sentido.

Os currículos, os espaços educativos, os materiais didáticos, o mobiliário e os equipamentos também não atendem, de maneira eficaz, à nova faixa etária do Ensino Fundamental, da mesma forma como já não eram adequados a essa etapa do ensino, com oito anos de duração. Essa inadequação revela as concepções adultocêntricas enraizadas na sociedade e descritas por autores como Áries (1981), Kuhlmann (2002), os quais entendem a infância não como um período marcado pela imaturidade do sujeito, mas como uma construção social.

Na contramão dessas concepções instaladas na educação brasileira, o enfoque históricocultural vê a criança como sujeito de sua atividade, capaz e competente na sua relação com o 
mundo (MELLO, 2007). A infância, por sua vez, em lugar de ser entendida como um acontecimento estático, mergulhado em um vazio social, é vista como um fenômeno concreto e, por isso, mediado, num processo dialético, por temas sociais, culturais, políticos e econômicos do mundo contemporâneo.

Autores como Vygotsky (1991), Leontiev (1978), Elkoni (1998), Mello (2007) apontam uma concepção de criança na qual as mudanças qualitativas ocorridas no psiquismo decorrem do conjunto complexo de sua atividade na relação com o entorno social. Nessa dinâmica, a criança apropria-se da cultura e da história da humanidade, processo este que a encaminha para uma nova situação social, levando-a à interpretação e à reprodução do especificamente humano. Assim, ela modifica seu psiquismo num todo sistêmico, pois ao mesmo tempo em que vive para si transformações, também transforma seu meio cultural. O movimento permanente dessas modificações indica a estruturação de todo o conjunto de sua personalidade.

A cada nova etapa de apropriação e internalização das funções tipicamente humanas, a criança passa a ocupar um novo lugar nas relações sociais, e cada um deles também provoca mudança em sua conexão com a sociedade. Tal processo reflete diretamente na modificação e na motivação da atividade, conduzindo a criança a uma reinterpretação de suas ações anteriores, modificando-as (MELLO, 2007). As transformações vividas levam-na a uma nova situação social, ou a uma nova posição no mundo das relações com seu entorno. Portanto, longe de ser passiva, é na sua atividade em interação com a história, com a produção material e não material e a sociedade humana que a criança se desenvolve psiquicamente e se reconhece como membro da cultura. $A$ concepção de criança, na perspectiva histórico-cultural, se sustenta na tese de que ela só se desenvolve, isto é, se humaniza, mediante a apropriação da cultura e no processo de sua atividade. De acordo com Mello (2007), o conceito de humanização refere-se ao processo de formação das qualidades humanas produzidas histórica e coletivamente pelo conjunto de homens.

Todas as habilidades e aptidões humanas são, nesse sentido, formadas nas relações entre o homem e o mundo da cultura, tornando-se produtos e produtoras da história humana. Consequentemente, a criança, nessa perspectiva, não nasce com caráter humanizado, mas se humaniza pelas suas experiências de vida e de educação (LEONTIEV, 1978).

Tomando por base essa forma de conceber a infância, com clareza da historicidade desse conceito que toma a criança como sujeito da sua atividade, é preciso investir em pesquisas que propiciem a interlocução com a realidade educacional, contribuindo para a compreensão crítica dos fatores limitadores da aprendizagem e da formação da criança, bem como para a produção de 
conhecimentos que subsidiem a construção de práticas educativas de valorização da infância e de respeito à criança como sujeito de direitos. Para tanto, o objetivo deste artigo é apresentar os principais resultados de uma pesquisa que envolveu a análise de trabalhos acadêmicos sobre o Ensino Fundamental de nove anos. Tal objetivo parte da premissa que instituições desse nível educacional e educadores do primeiro ano sentem dificuldades na apropriação dessa nova realidade em curso na educação brasileira.

A produção de conhecimentos, nesse âmbito, poderá auxiliar o processo de transformação da realidade estudada, abrindo caminho para a melhoria da qualidade da educação oferecida às crianças, cuja urgência é notória e indispensável, principalmente, conforme destacamos, no contexto de mudança estabelecido pela ampliação do Ensino Fundamental para nove anos.

\section{METODOLOGIA}

A partir da matriz epistemológica de corte histórico cultural, que concebe a criança como um sujeito histórico e localizado culturalmente, realizamos um levantamento da produção de dissertações de mestrado e de teses de doutorado defendidas entre os anos de 2006 e 2011 em Programas de Pós-Graduação em Educação com a temática do Ensino Fundamental de nove anos. Tal levantamento teve a intenção de subsidiar e fundamentar a presente pesquisa além de proporcionar o conhecimento sobre a produção acadêmica da temática em questão e suas principais contribuições para o campo da Educação em geral e, especialmente, para o campo de estudos do Ensino Fundamental.

As dissertações e as teses foram localizadas na internet por meio dos bancos de dados da CAPES (Coordenação de Aperfeiçoamento de Pessoal de Nível Superior), da BDTD (Biblioteca Digital Brasileira de Teses e Dissertações), do CNPq (Conselho Nacional de Desenvolvimento Científico e Tecnológico) e do Domínio Público. Na pesquisa bibliográfica realizada, foram utilizados os seguintes descritores: "Brincadeira e Ensino Fundamental de nove anos", "Educação Infantil e Ensino Fundamental", os quais poderiam estar localizados no título ou no resumo do trabalho. Nosso corpus de análise soma um total de quarenta e seis trabalhos sendo quarenta e duas dissertações de mestrado (91,3\%) e quatro teses de doutorado $(8,7 \%)$.

Em relação ao período estabelecido para o levantamento desses dados - a partir de 2006 determinanos tal ano em razão da promulgação da Lei no 11.274/06, que instituiu o Ensino Fundamental de nove anos. No sentido de embasar a nossa investigação, procuramos identificar 
nas teses e nas dissertações localizadas: 1) os temas investigados; 2) as abordagens metodológicas adotadas; 3 ) os sujeitos pesquisados e; 4) as questões passíveis de novas investigações.

\section{RESULTADOS E DISCUSSÕES}

O diagnóstico realizado perante as dissertações e teses defendidas pelos programas de pós-graduação em educação durante o período de 2006 a 2011, as quais compuseram nosso corpus de análise, evidenciaram de maneira substancial contribuições e reflexões para o campo do ensino fundamental e aprofundou a discussão em relação ao ensino de nove anos.

Análises qualitativas demonstraram que, embora os estudos tenham sido realizados a partir de problemas e procedimentos metodológicos distintos, foi unânime o reconhecimento de que o ensino fundamental de nove anos implantado ocorreu com muitas limitações e/ou precariedade quanto à reorganização dos espaços, tempo, atividades, estratégias e recursos, permanecendo com praticamente a mesma estrutura típica das primeiras e segundas séries do modelo de ensino fundamental anterior.

A ampliação do Ensino Fundamental se concretizou, via de regra, sem o necessário planejamento e construção de condições de atendimento às crianças que nele ingressaram; as transformações ocorreram, prioritariamente no âmbito administrativo, frequentemente restritras às matrículas das crianças de seis anos nesse nível de ensino. Para Kramer (2006) a mudança apenas burocrática é o que muitas vezes minimiza a potencialidade da escola, inferiorizando o que seria capaz de ampliar o conhecimento dos alunos: a experiência com a cultura.

Nesse sentido, as pesquisas apontam que os problemas do Ensino Fundamental de nove anos perpassam pela constituição de um currículo que proporcione à criança de seis anos de idade a experiência com a cultura e, sobretudo, nessa dimensão a valorização do brincar nesse nível de ensino. Em relação a essa questão, dos quarenta e seis trabalhos pesquisados, 19 deles, ou seja, $41,3 \%$ do total, indicaram escassez da atividade lúdica no espaço escolar e reconheceram a relevância de sua inserção na rotina das crianças.

Zingarelli (2009), ao investigar a diferença entre o processo de ensino e de aprendizagem das crianças de seis anos inseridas no ensino fundamental de nove anos de duração, nas instituições públicas e nas instituições privadas de ensino chegou a conclusão que as mudanças foram mais efetivas nas escolas públicas municipais do que nas escolas privadas.

Em relação à brincadeira, Zingarelli (2009) aponta que a mudança do ensino fundamental reduziu significamente os períodos destinados ao brincar. Na visão da autora (2009, p. 128), “na 
educação infantil o brincar era amplamente valorizado [...], já no Ensino Fundamental há um desprezo a atividades lúdicas e estas são entendidas como atividades para passar o tempo". Esse movimento de desvalorização da atividade lúdica têm tornado-se habitual nas instituições de ensino fundamental, visto que essa etapa está caracterizada e marcada historicamente pela atividade de estudo (ZINGARELLI, 2009).

Já Marega (2010), diante da recente inclusão da criança de seis anos no ensino fundamental e das dúvidas presentes na prática escolar com relação à organização do ensino para as crianças nesta faixa etária, procurou demonstrar de que forma o ensino para crianças de seis anos pode ser organizado levando em conta a transição da atividade lúdica para a atividade de estudo. Para tanto, a autora (2010), fundamentou-se nos estudos da Teoria Histórico-Cultural que destaca o papel ativo do sujeito na produção e apropriação do conhecimento. Nesse movimento, Marega (2010) destaca a necessidade da condução pedagógica desse processo de transição. Ressalta, ainda, que apesar de a atividade lúdica e a atividade de estudo não apresentarem as mesmas propriedades, ambas têm uma característica comum: o conteúdo.

Para a autora (2010) existem conteúdos no brincar e no estudar e, portanto, no momento de transição entre essas atividades é interessante não sobrepor uma atividade sobre a outra, dicotomizando-as como uma ligada ao prazer, outra à obrigação, dividindo os tempos e espaços destinados a cada atividade.

A partir dessas explanações e aprofundamentos sobre as Teses e Dissertações defendidas entre 2006 e 2011, reiteramos a necessidade de maior discussão nos programas de pós-graduação em relação as reações das crianças perante a sua inserção no primeiro ano do Ensino fundamental. A análise dos textos e pesquisas evidenciaram a falta de discussão em relação a interação das crianças; observação das atividades realizadas no primeiro ano; tempo e espaço/rotina; conteúdos e propriedades específicas do trabalho pedagógico nessa etapa.

O balanço bibliográfico demonstra que o estudo do imperativo legal da ampliação do Ensino Fundamental de nove anos é um assunto recorrente nas pesquisas. No entanto, o levantamento realizado revela que poucas pesquisas retratam as vivências e experiências das crianças nesse novo contexto. Apesar de muitos estudos afirmarem que o objeto da pesquisa é a criança, na verdade, são poucos que realmente a consideram-a como sujeito do processo. 


\section{CONSIDERAÇÕES FINAIS}

No processo de análise das pesquisas ficou evidente que o processo de implementação de nove anos no Ensino Fundamental, sobretudo, a inserção da criança aos seis anos de idade ainda representa um longo caminho a ser percorrido, visto que as mudanças e adaptações da infraestrutura, do tempo, do espaço, dos recursos e do currículo permaneceram praticamente as mesmas que as do Ensino Fundamental de oito anos, em várias unidades escolares das diferentes regiões do Brasil. Nessa direção, as práxis pedagógicas encontram-se cristalizadas no modelo tradicional e propêdeutico de ensino, contrariando as orientações previstas na implementação do Ensino Fundamental de nove anos.

Em relação a organização curricular identificou-se que a estrutura ainda é disciplinar, fragmentada e sequencial e no cotidiano escolar prevalece a relação hierárquica, com métodos de memorização, repetição e mecanização, contribuindo para a desconstrução da autonomia dos alunos e (ao menos relativo) desrespeito às suas peculiaridades. Por outro lado, existe uma acentuada preocupação com a alfabetização e letramento das crianças de seis anos, desconsiderando-se as atividades lúdicas e colocando-as em segundo plano.

Diante desse cenário, fica evidente que os currículos, os espaços educativos, os materiais didáticos, o mobiliário e os equipamentos também não atendem, de maneira eficaz, à nova faixa etária do Ensino Fundamental, da mesma forma como já não eram adequados a essa etapa do ensino, com oito anos de duração. Essa inadequação revela as concepções adultocêntricas enraizadas na sociedade e descritas por autores como Áries (1981) e Heywood (2004), os quais entendem a infância não como um período marcado pela imaturidade do sujeito, mas como uma construção social.

Nessa perspectiva concluímos, através do balanço bibliográfico, que a implementação do Ensino de nove anos, nos contextos pesquisados, foi elaborado sem planejamento e condições necessárias, evidenciando o que outros estudos indicam ser recorrente no panorama nacional, em perspectiva histórica: discrepâncias entre o discurso das políticas públicas e as práticas pedagógicas possíveis de serem materializadas no cotidiano escolar.

\section{REFERÊNCIAS}

ARCE, A. DUARTE, N. Brincadeira de papéis sociais na Educação Infantil: as contribuições de Vygotski, Leontiev e Elkonin. São Paulo: Xamã, 2006.

ARIÈS, P. História Social da Criança e da Família. Rio de Janeiro, Zahar, 1981. 
. Lei no. 10.172, de 9 de janeiro de 2001. Aprova o Plano Nacional de Educação e dá outras providências. Arquivos, Brasília, DF, 2001.

. Lei no. 11.274, de 6 de fevereiro de 2006. Altera a redação dos artigos 29, 30, 32 e 87 da Lei $n$ ‥ 9.394, de 20 de dezembro de 1996, que estabelece as diretrizes e bases da educação nacional, dispondo sobre a duração de 9 (nove) anos para o ensino fundamental, com matrícula obrigatória a partir dos 6 anos de idade. Diário Oficial [da] República Federativa do Brasil, Brasília, DF, 2006.

ELKONIN, D. B. Psicologia do jogo. São Paulo: Martins Fontes, 1998.

KRAMER, S. As crianças de 0 a 6 anos nas política educacionais brasileiras: Educação Infantil e/é Fundamental. Educ. Soc., Campinas, vol. 27, n. 96 - Especial, p. 797-818, out. 2006. Disponível em <http://www.cedes.unicamp.br>. Acesso em: 05 jul. 2010.

LDB - Lei de Diretrizes e Bases da Educação Nacional - Lei 9.394/96. Rio de Janeiro: DP\&A, 2001. 4.ed

LEONTIEV, A. N. O desenvolvimento do psiquismo. Tradução de Manuel Dias Duarte. Lisboa: Livros Horizonte, 1978.

MAREGA, A. M. P. A criança de seis anos na escola: transição da atividade lúdica para a atividade de estudo. Maringá, 2010. Dissertação (Mestrado em Educação), Programa de Pós-graduação em Educação, Universidade Estadual de Maringá, Maringá, 2009.

MELLO, S. A. Infância e humanização: algumas considerações na perspectiva histórico-cultural. In: PERSPECTIVA, Florianópolis, v. 25, n. 1, 83-104, jan./jun. 2007.

VYGOTSKY, L. S., LURIA, A. R., LEONTIEV, A. N. Linguagem, desenvolvimento e aprendizagem. 4. ed. São Paulo: Ícone: EDUSP, 1988.

VYGOTSKY, L. S. A formação social da mente. 4.ed. São Paulo: Martins Fontes, 1991.

ZINGARELLI, J. E. B. A ampliação do Ensino Fundamental de nove anos na escola pública e na escola privada: A experiência de Araraquara. São Carlos - UFSCar, 2009. Dissertação (Mestrado em Educação) Faculdade de Educação da Universidade Federal de São Carlos, São Carlos/SP, 2009. 